Corresponding Author: Imma Ayu Riani; email:

immaayu04@gmail.com

Published: 7 February 2022

Publishing services provided by Knowledge E

(c) Mikawati Mikawati et al. This article is distributed under the terms of the

Attribution License, which

permits unrestricted use and redistribution provided that the original author and source are credited.

Selection and Peer-review under the responsibility of the IVCN Conference Committee.

\section{Anxiety in Pregnant Women During the COVID-19 Pandemic}

\section{Mikawati Mikawati, Muaningsih Muaningsih, Suriyani Suriyani, and Imma Ayu} Riani*

Department of Nursing, Sekolah Tinggi Ilmu Kesehatan Panakukang, Makasar, Indonesia

\section{ORCID}

Imma Ayu Riani: https://orcid.org/0000-0003-3035-542X

Abstract. The World Health Organization declared COVID-19 as a pandemic because of its rapid and extensive spread. Pregnant women are one of the groups vulnerable to COVID-19, and COVID-19 can have an impact on their psychology, including anxiety. The purpose of this study was to identify the level of anxiety in pregnant women, and the related factors, effects and efforts made in dealing with anxiety in pregnant women during the pandemic. The study involved a literature review, and 10 articles were included. These articles were found by searching for keywords including pregnancy, anxiety, Coronavirus, and COVID-19. Four of the articles discussed the anxiety levels of pregnant women during the COVID-19 pandemic, two articles discussed factors related to this anxiety, two articles discussed the effects of this anxiety, and two articles discussed the efforts of pregnant women to handle their anxiety during the pandemic. According to the results, most of the pregnant women experienced psychological changes and an increase in anxiety during the COVID-19 pandemic. The factors that affected the level of anxiety included a lack of family support, social isolation, and geographical differences.

Keywords: pregnant woman, anxiety, COVID-19, literature review

\section{Introduction}

In December 2019 the Covid-19 virus was discovered in Wuhan City, China. WHO has declared it a pandemic outbreak because it spreads so fast and occurs in many countries [1]. 220 countries reported the number of people who were positively infected with COVID-19. On December 7, 2020, WHO received reports of 66,422,058 confirmed cases of COVID-19, with a death toll of 1,532,418 [2]. Indonesia reported that on December 7, 2020, there was an increase in cases from previously reported data, on November $26,2020,581,550$ confirmed cases of coronavirus were confirmed, 479,202 were declared cured and 17,867 cases died [3]. Positive cases of coronavirus based on data from South Sulawesi (South Sulawesi Responding to COVID-19, 2020) on December 7, 2020, there were 21,914 cases, 18,984 cases recovered, and 508 cases died, an increase from the previous data reported on December 1, 2020. For the Covid-19 case 
that occurred in Makassar, the number of confirmed positive cases was 15,300 cases, 9,296 recovered, and 316 died.

Seeing the current situation, the COVID-19 pandemic has made pregnant women a vulnerable group at risk for COVID-19 and has an impact on psychology, one of which is anxiety, in addition to feeling anxious about their pregnancy, there are other risk factors that arise, namely environmental insecurity related to disaster or disaster events. early [4]. Concerns felt by pregnant women about the risk of infection during pregnancy, transmission to the baby and family members [5]. The impact of COVID-19 that attacks the community and pregnant women in general is almost the same, symptoms such as cough, fever, nasal congestion, sore throat, and an average of 8 days the patient will show symptoms of dyspnea [6]

Pregnant women will find complications in the fetus as well as stunted fetal growth (IUGR) (9\%), stillbirth (2\%), and preterm delivery (43\%) [7]. This will affect the fetus, related to neonatal growth and development. So that special attention is needed for pregnant women regarding prevention, diagnosis, and management [8]. Some of the suggested ways to reduce the psychological impact of anxiety on pregnant women during the COVID-19 pandemic are staying in therapeutic contact with the provision of health services using existing technological facilities, conducting cognitive behavioral therapy (CBT) by means of talk therapy, improving coping skills and changing patterns. think and do self-care by means of yoga, meditation, exercise, adequate sleep, nutrition and vitamins [9].

\section{Methods}

In this study, the literature review method uses several databases and gray search with high to low quality criteria, namely, Google Scholar, Clinicalkey For Nursing, Science Direct, and ProQuest. By using keywords: pregnant women, anxiety, COVID-19. Then journals or articles that match the inclusion and exclusion criteria are taken for further analysis. The results of a literature search conducted on four databases using predetermined keywords, then the researchers found 1,399 articles that matched these keywords. The search results that have been obtained are then checked for duplication, it is found that there are no similar articles so that the articles are still the same in number of 1,399 articles. Researchers then conducted screening or selection since 2020 , based on full text and journal articles so that the number selected $(n=16)$. The articles that were assessed for feasibility were 10 which were adjusted to the theme of the literature review. The assessment was carried out based on the feasibility with inclusion and 


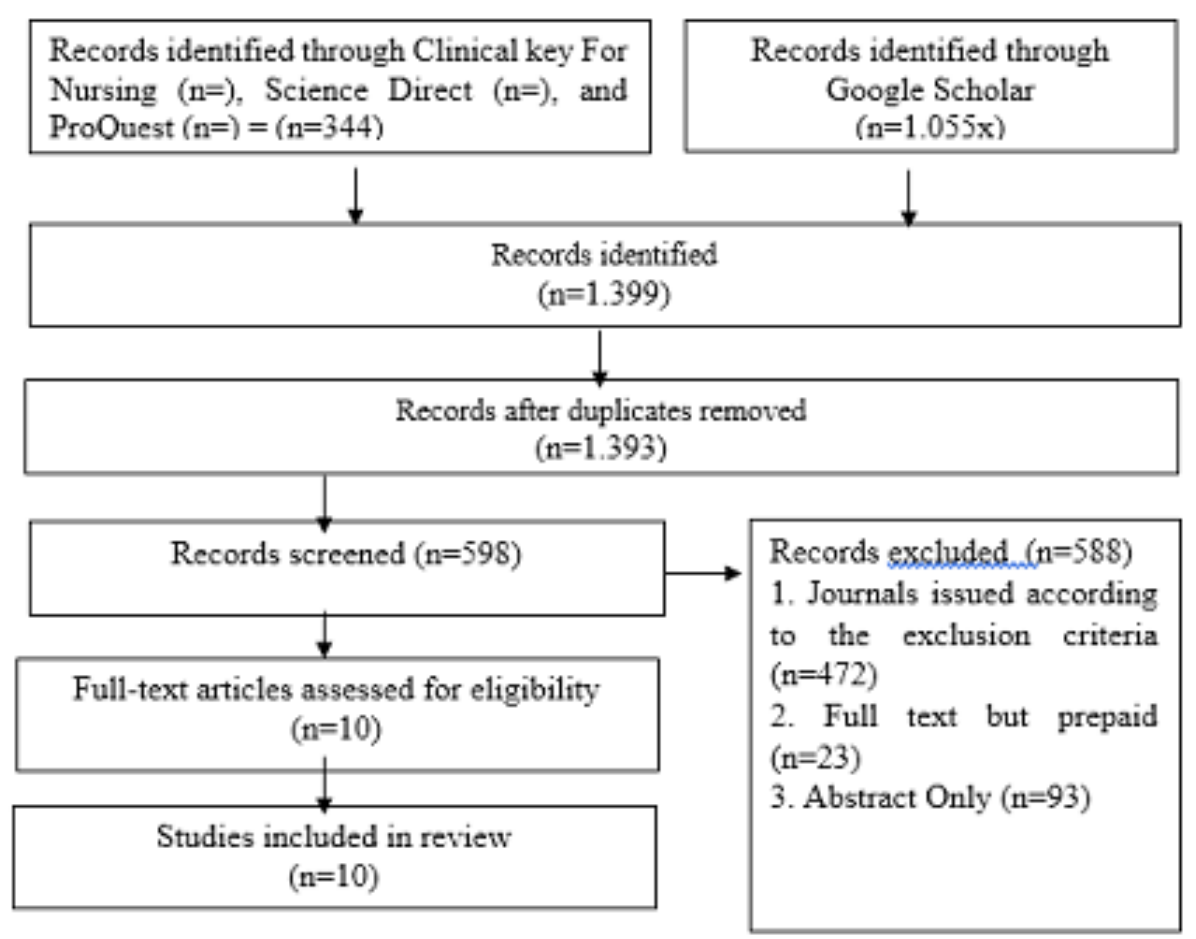

Figure 1: PRISMA Flow Chart.

exclusion criteria obtained as many as 10 articles that will be used in the preparation of the literature review.

\subsection{Inclussion criteria}

The following criteria were used to determine whether studies should be included or excluded from the review: 1). Pregnant woman. II) Prevention of anxiety in the COVID19 pandemic. III) No comparison. IV) Anxiety in pregnant women, Levels of anxiety in pregnant women, things that affect the level of anxiety in pregnant women. $V$ ) Quasai experimental, Cross Sectional, Anonymous survey, Case control, observational descriptive, qualitative descriptive, descriptive, Quantitative analysis, literature review. VI) Year 2019-2020. VII) Bahasa and English

\section{Results}

In compiling this literature review, there are ten journal articles that have been selected by researchers using inclusion criteria related to the level of anxiety of pregnant women during the COVID-19 pandemic. Of the ten selected journals, there are three national 
journals and seven international journals that discuss the level of anxiety of pregnant women during the COVID-19 pandemic.

Of the ten selected journals, there are three national journals and seven international journals that discuss the level of anxiety of pregnant women during the COVID-19 pandemic.

\section{Discussion}

\subsection{Identifying the level of anxiety in pregnant women during the COVID-19 period}

In a study conducted by [10] when comparing the results of the presentation of the prevalence of anxiety symptoms, the results of the percentage prevalence of anxiety during pregnancy were generally $18-25 \%$. And $59 \%$ results during the COVID-19 pandemic. There is an increase in anxiety in pregnant women because pregnant women are more worried about not getting treatment and being exposed to disease.

Research conducted [11], where the results in Canada were 31\% of pregnant women experienced stress and symptoms of depression appeared from 129 respondents who were quarantined pregnant women. As many as 53.8\% of pregnant women in Wuhan, China were found with psychological disorders $17 \%$, anxiety and major depression $29 \%$. It was also found by [11] that out of 16 articles, there were 10 articles discussing increased anxiety.

The results of this study are also strengthened by [17]) that during the COVID-19 pandemic, most pregnant women show negative emotions such as anxiety which shows the mother's concern, if anxiety cannot be overcome, it will cause anxiety. continuous stress, feelings experienced by pregnant women with feelings of depression during the COVID-19 pandemic, if left for a long period of time it will have an impact on symptoms of depression, where the condition of pregnant women has feelings of hopelessness, helplessness and will greatly affect the fetus mother, compared to positive emotions.

\subsection{Things that affect the anxiety level of pregnant women during the COVID-19 period}

In the research conducted [13], the results obtained from 71 respondents who affected anxiety in pregnant women during the COVID-19 period, namely worrying about the dangers of contracting COVID-19 to children who exist and have the elderly at home 
TABLE 1

[10]

Design: Literature Review Population Pregnant Women Variable : Description of the anxiety level of pregnant women during the COVID-19 pandemic.

[12] Pregnant women Variable: Psychological response of pregnant women during the COVID-19 pandemic

3] Design : Quantitative Descriptive Population : Pregnant Women Variable: isola Health anxiety and behavioral changes work, $19.7 \%$ (14/71) choose to work at home in pregnant women during the COVID19 pandemic

[14] Design : Cross-sectional survey Popula tion : Pregnant Women Variables: Risk factors for symptoms of depression, anxiety, and PTSD in pregnant women during the covid-19 pandemic

[15] Design : Cross-sectional survey Pop- Syn ulation : Pregnant Women Variable : improved compared to similar symptoms. The group of preSymptoms of depression and anxiety in pandemic pregnant women with $37 \%$ reported clinically relevant pregnant women during the COVID-19 depressive symptoms and 57\% reported clinically relevant pandemic.

[16] Design : Quasi-Experimental Popula- $A$ tion: Pregnant women Variables: Birth planning during COVID-19 with prenatal disorders and anxiety of pregnan women.

[17] Design : Cross-sectional survey Population: Pregnant women Variable: Fear that were positively and significantly correlated with mental and anxiety of COVID-19 mental health health, and COVID-19 anxiety also had the highest positive in pregnant women

[18] Design : Descriptive statistics Population: Pregnant women Variable : Effects of the COVID-19 pandemic on anxiety and depressive symptoms

Design : Qualitative description Population: Pregnant women Variable
Perinatal anxiety and depression during COVID-19
In the study anxiety symptoms (59\%) increased above the threshold score based on a previous pre-COVID-19 cohor that assessed symptoms in pregnant women with similar demographic profile. The increased level of anxiety sy in this high group of pregnant women suggest particular concern to expectant mothers. Report comparisons of pregnancy anxiety data with meta-analyses reporting a prevalence of $18-25 \%$ and a prevalence of $16 \%$ in the US genera population.

In Canada, out of 129 pregnant women who were quarantined $31 \%$ of respondents experienced post-quarantine stress and symptoms of depression. According to a study conducted in Wuhan, China, $53.8 \%$ of pregnant women experienced psychological disorders, $17 \%$ and $29 \%$ experienced major depression and anxiety symptoms.

Of the 16 articles, namely 10 articles discussing increasing anxiety in the area of the highest Covid-19 cases, 5 articles discussing the stress of pregnant women during the COVID 19 period, and 3 articles discussing the factors of depression in pregnant women during the COVID-19 period.

Results $36.4 \%$ of respondents reported clinically significant rates of depression, $22.7 \%$ for generalized anxiety, and $10.3 \%$ for PTSD. About $18 \%$ reported a high level of COVID-19-related health concern and were 2.6 to 4.2 times more likely to score above the clinical threshold for mental health symptoms. anxiety symptoms.

A total of 96 respondents Tele-education was offered to pregnant women about pregnancy and delivery planning during COVID-19, the average score of 48 pregnant women in the experimental group and 48 pregnant women in the control 8.75 \pm 5.10 and $11.50 \pm 4,91$

COVID-19 anxiety and worry during pregnancy were variables direct effect, the correlation between them $(B=0.32)$. The variable of happiness in the experience of pregnancy which has a significant, negative relationship with mental health disorders $(B=0.29)$ with fear of COVID-19 through an indirect route $(B=0.05)$. Thus, that fear of COVID-19 has a direct effect on COVID-19 anxiety.

Results respondents $35.4 \%$ higher, Edinburgh postpartum depression (EPDS). A group comparison by year of education showed statistically significant COVID-19 on psychology, socia isolation, and mean scores in the Beck Depression Inventory (BDI) and Beck Anxiety Inventory (BAI). The condition was more severe in the case group than in the control group (psychology).

The outbreak of the COVID-19 viral disease puts perinata women at a higher risk for developing anxiety and depression. Uncertainty, fear, and confusion in the medical, social, economic, occupational, and political aspects of life add to the stressors experienced by perinatal women. 
because children and the elderly have susceptibility to COVID-19 transmission, the supply of food, drink, and toiletries that must be met in the household every day changes during the COVID-19 pandemic due to having to isolate at home to maintain a distance of making food supplies and food that has to be bought more than usual and runs out quickly makes pregnant women feel worried, Child allowances or child costs such as those who are still in education for pregnant women and husbands who work but have to lose their jobs due to the impact of the COVID-19 pandemic so that it becomes one of the causes that make pregnant women feel worried for their children, and pregnant women think about the impact ak to the fetus itself, if the mother is positive for COVID-19 what about the fetus being conceived, whether the health of the fetus will be infected or not.

In addition, research conducted by [14] showed high anxiety results with factors about the first child where a woman who had just felt like a mother but had to experience a COVID-19 pandemic, the anxiety felt by pregnant women also on income that is not commensurate with the needs that must be fulfilled, children's education with the addition of internet fees that must be available, and the health of families at home and distant relatives.

\subsection{The effect of anxiety on pregnant women during the COVID-19 period}

Research by [18] found that the effects experienced by pregnant women during the COVID-19 pandemic were due to social isolation.

The results of the study were strengthened by [15] with the assessors of the results obtained from 1987 respondents, namely pregnant women experiencing changes in prenatal care who previously visited the hospital four times to three times, pregnant women also experiencing job losses due to the impact of the COVID-19 pandemic carried out by these companies, experiencing social isolation experienced by pregnant women to carry out social activities in the surrounding environment and only doing activities at home, pregnant women worry about threats to their babies such as stunted fetal growth, stillbirth or stillbirth, and premature delivery, pregnant women also feel a threat to their lives because they are very vulnerable to contracting COVID-19 and seeing the situation where there is an increase in deaths exposed to COVID-19. 


\subsection{Efforts to handle the anxiety level of pregnant women during the COVID-19 period}

Research by [9]using tele-health as a communication tool in providing health care to pregnant women via video and telephone. The treatment provided includes education related to anxiety felt by pregnant women, changing thought patterns, cognitive behavioral therapy, breathing techniques, yoga, meditation, light exercise, and the need for family support.

In the research conducted [16], using tele-education for pregnant women. A total of 96 pregnant women were divided into the experimental group as many as 48 respondents and the control group as many as 48 respondents, the results of this study showed that in the experimental group there was a decrease in anxiety for pregnant women who received tele-education regarding pregnancy and birth planning during the COVID-19 pandemic, while in the control group there was no change in pregnant women who did not receive tele-education.

\section{Conclusion}

Based on literature reviews from ten research journals, it can be concluded, identifying the level of anxiety in pregnant women during the COVID-19 period, it was found that based on the figures obtained high levels of anxiety in pregnant women during the COVID-19 pandemic, this could have a serious impact on the condition of the mother and fetus. . Things that affect the level of anxiety of pregnant women during the COVID-19 period are caused by various factors that have existed before and after the current COVID-19 pandemic conditions, groups who are vulnerable to COVID-19, social isolation, lack of support from family and relatives, and socioeconomic. The effects on pregnant women during the COVID-19 period are feeling the limitations of activities that are only carried out at home, the needs that must be fulfilled during the COVID-19 pandemic, changes in the schedule of visits to control the content, and changes in social support in the form of material and spiritual. Efforts to handle the anxiety level of pregnant women during the COVID-19 period by using tele-halth and tele-education that can use technology as treatment that is used remotely. 


\section{References}

[1] Yuliana Y. Corona virus disease (Covid-19): A literature review. Weleness Heal Mag. 2020;2:124-137.

[2] World Health Organization. Coronavirus disease (COVID-19). WHO.

[3] Kementrian Kesehatan. Jumlah korban covid-19. 2020.

[4] Kajdy A, Feduniw S, Ajdacka U, et al. Risk factors for anxiety and depression among pregnant women during the COVID-19 pandemic: A web-based cross-sectional survey. Medicine (Baltimore). 99.

[5] Panahi L, Amiri M, Pouy S. Risks of novel coronavirus disease (COVID-19) in pregnancy; A narrative review. Archives of academic emergency medicine. 8.

[6] Guan W, Ni Z, Hu Y, et al. Clinical characteristics of coronavirus disease 2019 in China. New England journal of medicine. 2020;382:1708-1720.

[7] Dashraath P, Wong JLJ, Lim MXK, et al. Coronavirus disease 2019 (COVID19) pandemic and pregnancy. American journal of obstetrics and gynecology. 2020;222:521-531.

[8] Goyal K, Chauhan P, Chhikara K, et al. Fear of COVID 2019: First suicidal case in India.

[9] Chen H, Selix N, Nosek M. Perinatal anxiety and depression during COVID-19. The Journal for Nurse Practitioners. 2021;17:26-31.

[10] Tantona MD. Anxiety disorders in pregnant women during Covid-19 pandemic. Jurnal Penelitian Perawat Profesional. 2020;2:381-392.

[11] Purwaningsih H. Analisis masalah psikologis pada ibu hamil selama masa pandemi Covid-19: Literature review. Paper presented at: Seminar nasional kebidanan; 2020. $7 p$.

[12] Wulandari SR, Melina F, Kuswanti I, et al. Respon psikologis perempuan hamil selama masa pandemi covid-19. Jurnal Kesehatan. 11.

[13] Corbett GA, Milne SJ, Hehir MP, et al. Health anxiety and behavioural changes of pregnant women during the COVID-19 pandemic. European journal of obstetrics, gynecology, and reproductive biology. 2020;249:96.

[14] Liu CH, Erdei C, Mittal L. Risk factors for depression, anxiety, and PTSD symptoms in perinatal women during the COVID-19 pandemic. Psychiatry research. 2021; 295:113552.

[15] Lebel C, Mackinnon A, Bagshawe M, et al. Elevated depression and anxiety symptoms among pregnant individuals during the COVID-19 pandemic. Journal of affective disorders. 2020;277:5-13. 
[16] Derya YA, Altiparmak S, Emine A, et al. Pregnancy and birth planning during COVID19: The effects of tele-education offered to pregnant women on prenatal distress and pregnancy-related anxiety. Midwifery. 2021;92:102877.

[17] Salehi L, Rahimzadeh M, Molaei E, et al. The relationship among fear and anxiety of COVID-19, pregnancy experience, and mental health disorder in pregnant women: A structural equation model. Brain and behavior. 2020;10:01835.

[18] Durankus F, Aksu E. Effects of the COVID-19 pandemic on anxiety and depressive symptoms in pregnant women: A preliminary study. The Journal of Maternal-Fetal \& Neonatal Medicine. 2020:1-7. 